\title{
On-chip electrochemical microsystems for measurements of copper and conductivity in artificial seawater.
}

Grégoire Herzog, ${ }^{1,2,3 *}$ Waleed Moujahid, ${ }^{1}$ Karen Twomey, ${ }^{1}$ Conor Lyons, ${ }^{1}$ and Vladimir I. Ogurtsov $^{*}$

1: Tyndall National Institute, University College Cork, 'Lee Maltings', Cork, Ireland.

2: Present address: Université de Lorraine, LCPME, UMR 7564, Villers-lès-Nancy, F-54600, France

3: Present address: CNRS, LCPME, UMR 7564, Villers-lès-Nancy, F-54600, France

* Corresponding authors: (GH) gregoire.herzog@lcpme.cnrs-nancy.fr; T: + 333836852 54; (VIO) vladimir.ogurtsov@ tyndall.ie ; T+353 214904271.

This document is a postprint. Final version has been published in Talanta, 2013, 116, 26-32 (https://doi.org/10.1016/j.talanta.2013.04.057).

Abstract: The fabrication and characterisation of microelectrochemical sensors for $\mathrm{Cu}^{2+}$, dissolved oxygen and conductivity suitable for operation in the marine environment are presented. The impact of the designs on sensor performance and their adequacy to operate in real conditions are discussed. The sensors are fabricated on silicon using photolithographic and thin film deposition techniques. They represent a complete microelectrochemical cell tailored to voltammetric, amperometric and impedimetric measurements. The impedimetric sensor is made of $\mathrm{Pt}$ interdigitated electrodes which are used for the measurement of conductivity. The amperometric and voltammetric sensors are based on a three electrode electrochemical cell with on-chip $\mathrm{Ag} \mid \mathrm{AgCl}$ reference and $\mathrm{Pt}$ counter and working electrodes, used for detection of oxygen and copper. Dissolved oxygen is detected by chronoamperometry; $\mathrm{Cu}^{2+}$ sensing is based on underpotential deposition - stripping voltammetry at microelectrode array. The sensor operated in the $\mathrm{Cu}^{2+}$ concentrations ranging from 0.48 to $3.97 \mu \mathrm{M}$ with a limit of detection of $0.115 \mu \mathrm{M}$. The impact of the temperature, the $\mathrm{pH}$ and the salinity of the artificial seawater on the sensitivity for $\mathrm{Cu}^{2+}$ detection are also considered. Measurements of copper concentration and conductivity are validated using certified reference materials and standard solutions. 


\section{Introduction}

Electrochemical methods are of particular interest for in-situ environmental applications as operating procedures remain simple and are without or with limited sample pre-treatment, which is essential for their implementation outside the laboratory. Miniaturised electrochemical sensors offer a number of advantages over macroscopic electrodes including (i) improved mass transport and hence increased sensitivity (due to the hemispherical diffusion); (ii) improved signal to noise ratio; (iii) reduced $i R$ drop [1]. Thus, microfabricated electrochemical sensors can provide sufficient sensitivity and achieve required limits of detection for practical applications due to improved mass transfer and signal to noise ratio. A number of miniaturised electrochemical sensors for autonomous in-situ measurements have been developed [2-9]. Autonomous electrochemical systems were devoted to the detection of heavy metals in sea water by either cathodic stripping voltammetry [2,3] (CSV) or anodic stripping voltammetry [4-7] (ASV). Concentration of dissolved oxygen in seawater has also been monitored using electrochemical sensors [8,9]. These types of sensors have been incorporated within autonomous monitoring systems for in-situ measurements [10]. More recently, wearable electrochemical sensors and instrumentation have been integrated into a watersport wetsuit [11]. Three types of amperometric sensors (for phenol, heavy metals and trace explosive) were incorporated in the garment. Chemical and physical sensors can be integrated in autonomous environmental monitoring systems, which allow the measurements of pollution and quality levels in fixed sampling locations [11-17].

In our previous studies, we have investigated the impact of the microelectrode array design on the cyclic voltammetry response of ferrocene monocarboxylic acid [18]. Such microelectrode arrays have also been modified with conducting polymers or thiols for the detection of hydrogenophosphate in organic solvents [19]. More recently, reference and counter electrodes were integrated into a single chip and characterised in artificial sea water by cyclic voltammetry of ferricyanide [20]. We report here the use of microfabricated electrochemical sensors for the measurement of $\mathrm{Cu}^{2+}$ concentration and conductivity in artificial seawater. $\mathrm{Cu}^{2+}$ has been selected as a model pollutant present in seawater, whereas conductivity can indicate indirectly the presence of pollution. Furthermore, sensitivity for $\mathrm{Cu}^{2+}$ can vary with conductivity value. Hence, it may be important to know the conductivity value to be able to correct the $\mathrm{Cu}^{2+}$ concentration measured. $\mathrm{Cu}^{2+}$ is detected by underpotential deposition - stripping voltammetry (UPD-SV) as it offers a number of advantages for electroanalytical applications [21]. Underpotential deposits only covers a small portion of the electrode surface, leaving the electrode surface mainly unchanged. At the maximum, one monolayer is deposited so the preconcentration times are short; finally, it is possible to detect metals in the presence of dissolved oxygen.

The microelectrochemical system was implemented with two types of microelectrochemical sensors fabricated using photolithographic techniques. The first type of sensor was a threeelectrode cell made of a platinum working microelectrode array, a $\mathrm{Ag} \mid \mathrm{AgCl}$ reference electrode and a platinum counter electrode. The second type was made of platinum interdigitated electrodes. The three-electrode cell was characterised by cyclic voltammetry of ferricyanide in artificial seawater and was subsequently used for UPD-SV of $\mathrm{Cu}^{2+}$ and for the 
reduction of dissolved oxygen. In the literature, the performance of miniaturised electrochemical sensors, and of microelectrode arrays are mostly evaluated and discussed based on cyclic voltammetry experiments [22,23]. However, this electrochemical method is seldom used for analytical applications due to its lack of sensitivity. Indeed, stripping voltammetry techniques at micro-electrode arrays are generally used for the detection of metals in solution [24]. The influence of the geometry of the microelectrode array (radius, spacing, number of electrodes) on the analytical response of $\mathrm{Cu}^{2+}$ UPD-SV is discussed in order to optimise the microelectrode array design to achieve the best analytical performance. Conductivity of artificial seawater was measured by application of electrochemical impedance spectroscopy at the interdigitated electrodes of different designs.

\section{Experimental}

\section{Microfabrication and microelectrochemical cell design}

The sensors designed for this work were: a three-electrode cell for voltammetric (copper) and amperometric (dissolved oxygen) detection and an interdigitated electrode pair for impedimetric measurements. The sensors were fabricated as described previously on individual chips [18-20].

The three-electrode Pt cell comprised a working microelectrode array, an L-shaped counter electrode and a pad for the reference electrode was fabricated at the first stage of the process (mentioned above). To prepare the reference electrode, a drop of silver paint was placed on the Pt pad, and the silver paint was cured at $120{ }^{\circ} \mathrm{C}$ for 1 hour. The silver paint is then oxidised by cyclic voltammetry in $1 \mathrm{M} \mathrm{KCl}$ between 0 and $1 \mathrm{~V}$ at scan rate $10 \mathrm{mV} \mathrm{s}^{-1}$ to form a $\mathrm{Ag} \mid \mathrm{AgCl}$ electrode. Eight working microdisc electrode arrays (named A1 to A8) in a hexagonal arrangement were designed with different numbers of electrodes in the array $(N=$ 4, 16, 64 or 256), different electrode radii ( $r=5,10,15$ and $20 \mu \mathrm{m})$ and different interelectrode spacing $(S=200$ and $400 \mu \mathrm{m}$ ). Four designs of interdigitated electrodes (named I1 to I4) for conductivity measurements were fabricated with varying geometrical parameters: electrode length, width and spacing. The geometric parameters of these designs are summarised in Table 1. Each fabricated chip was made of one electrochemical cell or one set of interdigitated electrodes.

\section{Electrochemical measurements and reagents}

All electrochemical experiments were performed in a Faraday cage and each measurement was carried out four times (unless stated otherwise). The sensors were cleaned beforehand in a plasma cleaner (Harrick Plasma, New-York, USA) for five minutes at high frequency at $100 \mathrm{~W}, 600$ mTorr. A CHI620A potentiostat of CH Instruments (purchased from IJ Cambria, Burry Port, Wales, UK), linked to a personal computer, was used for the voltammetric and amperometric studies. The stripping of the copper underpotential deposits was done by SW voltammetry with the following parameters: Amplitude: $25 \mathrm{mV}$; Frequency: $15 \mathrm{~Hz}$, Increment: $4 \mathrm{mV}$. Impedimetric measurements were performed by electrochemical impedance spectroscopy (EIS) using an Autolab PGSTAT302N electrochemical workstation from Metrohm Ltd. The temperature of the tested solutions was set at $25{ }^{\circ} \mathrm{C}$ using a 
LaudaEcoline Model E-200 circulator. EIS was performed over the frequency range $0.1 \mathrm{~Hz}$ to $1 \mathrm{MHz}$ at an applied potential of $0.2 \mathrm{~V} \mathrm{DC}$ bias and a $5 \mathrm{mV}$ AC amplitude.

All chemicals used in this study were purchased from Sigma-Aldrich Ireland Ltd and used as received. The electrolyte solution employed in the experiments was artificial seawater with the following composition: $400 \mathrm{mMNaCl}, 20 \mathrm{mM} \mathrm{MgCl}, 20 \mathrm{mM} \mathrm{MgSO}_{4}, 10 \mathrm{mM} \mathrm{CaCl}_{2}$ and $10 \mathrm{mMKCl}[25,26]$. The $\mathrm{pH}$ of the solution was adjusted to 6.5 by addition of $\mathrm{HCl}$. Control of $\mathrm{pH}$ was performed using a Benchop pH/ISE meter Model 520A (Orion Research Inc. USA) and was calibrated before each use. Artificial seawater of varied salinity was prepared according to ratios published by Hansson [27]. The reference material "LGC6016 Estuarine water - Traces metals" used for the $\mathrm{Cu}$ sensor validation was purchased from LGC Standards (UK) and represented estuarine water taken from the Seven Estuary, UK, offshore from a heavily industrialised area near Avonmouth. The conductivity sensors were characterised over a range of standard $\mathrm{KCl}$ solutions with conductivity values equal to $1.413,10.00,12.90$, 20.00 and $50.00 \mathrm{mS} \mathrm{cm}^{-1}$ within which the range of seawater conductivity coincides [28]. The conductivity standards were purchased from Sigma Aldrich and Reagecon Ltd. A standard conductometer (712 Conductometer from Metrohm, Switzerland) was used to measure the conductivity of artificial seawater and standard $\mathrm{KCl}$ solutions.

\section{Results and discussion}

\section{Characterisation of the microelectrochemical cell}

The fabricated microelectrochemical cells were tested by cyclic voltammetry of $1 \mathrm{mM}$ ferricyanide in artificial seawater at scan rate $10 \mathrm{mVs}^{-1}$ (Figure 1). In all cases, a sigmoidal shape was observed for each of the designs A, indicating an occurrence of hemispherical diffusion of the ferricyanide towards the microdiscs with absence of overlapping between the diffusion zones of neighbouring microdiscs for the timescale of the experiments. The limiting currents, $i_{L}$, obtained experimentally for the different designs by averaging of 6 experiments were then compared to the theoretical values calculated from Equation (1) [29]:

$$
i_{L}=\frac{4 \pi n F D C r^{2} N}{4 L+\pi r}
$$

Here, $n$ is the number of electron exchanged in the reaction $(n=1), F$ is the Faraday constant $\left(96,485 \mathrm{C} \mathrm{mol}^{-1}\right), D$ is the ferricyanide diffusion coefficient $\left(D=7.6 \times 10^{-6} \mathrm{~cm}^{2} \mathrm{~s}^{-1}[30]\right), C$ is the bulk concentration (in mol cm${ }^{-3}$ ), $r$ is the radius of the microdisc (in $\mathrm{cm}$ ), $N$ is the number of microdiscs in the array and $L$ is the recess due to the silicon nitride layer $\left(5 \times 10^{-5} \mathrm{~cm}\right)$. The equation implies that the microdiscs in the array are sufficiently spaced there is no overlap of the diffusion zones of neighbouring electrodes. The experimental and theoretical values of the limiting current were similar, which confirmed the adequate spacing and suitable fabrication process. Figure 1A shows the voltammograms for designs A1-4 with the number of microdiscs in the array varied from 4 to 256. The radius $(r)$ and spacing $(S)$ were kept constant $(r=10 \mu \mathrm{m}$ and $S=200 \mu \mathrm{m}$ ). The limiting currents increased linearly with the number of microdiscs in the array (inset of Figure 1A) with a slope of $2.3 \mathrm{nA}$ per electrode with a coefficient of determination $r^{2}=0.99998$. The experimental values of the limiting currents (in round brackets) in comparison with the theoretical ones obtained by using Equation (1) [in square brackets] were as follows: $(10.4 \pm 0.19) \mathrm{nA}$ vs. [11.0nA] for design 
$\mathrm{A} 1,(38.6 \pm 2.02) \mathrm{nA}$ vs. [44.1nA] for design A2, $(152 \pm 3.84) \mathrm{nA}$ vs. [176nA] for design A3 and $(594 \pm 4.87) \mathrm{nA}[706 \mathrm{nA}]$ for design A4. As one can see the theoretical limiting current exceeded the experimental data providing a discrepancy between current values in the range between $6 \%$ and $18 \%$. The discrepancy as the number of microdiscs in the array increased, which can be attributed to the presence of 'dead' or inactive $\mu$ discs in the array, which eventually lead to a lower limiting current $[31,32]$.

Figure 1B shows the voltammograms for designs A3, A5, A6 and A7, with the radius $r$ varied from 5 to $20 \mu \mathrm{m}$. The number of microdiscs in the array $N$ was equal to 64 , and the centre-to-centre spacing $S$ was kept equal to $20 r$. The limiting current values increased with increasing electrode radius as expected from equation (1). However, the current density increased when the radius decreased (see Inset in Figure 1B) due to the improved mass transport at microdiscs of smaller dimension. Once again, the experimental limiting current values were in reasonable agreement with the theoretical values: $(71.1 \pm 5.61) \mathrm{nA}$ vs. [83.3 $\mathrm{nA}$ ] for design $\mathrm{A} 5,(152 \pm 3.84) \mathrm{nA}$ vs. [176nA] for design $\mathrm{A} 3,(267 \pm 2.86) \mathrm{nA}$ vs. [270nA] for design A6 and (334 \pm 3.99$) n A$ vs. [364nA] for design A7 (discrepancy between current values was between 8 and $17 \%$ ). Once more, the theoretical limiting current exceeded the experimental data but in contrary to the previous findings, the discrepancy decreased as the number of microdiscs increased. Again this discrepancy is attributed to the presence of inactive electrodes in the array.

The influence of centre-to-centre spacing between neighbouring microdiscs on the limiting current is shown in Figure 1C by example of the array with $r=10 \mu \mathrm{m}$. The neighbouring microdiscs spacing $S$ was $20 r$ (design A3) and 40r (design A8). No significant differences between the experimental limiting currents were observed: $(152 \pm 3.84) \mathrm{nA}$ for design A3 and $(146 \pm 4.83) \mathrm{nA}$ for design A8.

\section{UPD-SV of $\mathrm{Cu}^{2+}$}

As preliminary experiments, a series of three UPD-SV scans was performed: (1) UPD-SV in artificial seawater in the absence of copper; (2) a UPD-SV of $1.5 \mu \mathrm{M} \mathrm{Cu}^{2+}$ in artificial seawater and (3) UPD-SV in artificial seawater in the absence of copper. After the third scan, a residual underpotential deposit of $\mathrm{Cu}$ was stripped from the surface of the electrode (data not shown). This indicated the need to introduce electrochemical steps to produce a fresh and clean electrode surface for the subsequent experiments. The potential waveform for the UPDSV procedure was the following [33]: (1) a preconditioning step at $+0.8 \mathrm{~V}$ for $5 \mathrm{~s}$; (2) a cleaning step at $+0.45 \mathrm{~V}$ for $45 \mathrm{~s}$; (3) a preconcentration step at $-0.15 \mathrm{~V}$ for 90 seconds; (4) a detection step by square wave voltammetry starting at $-0.15 \mathrm{~V}$ and finishing at $0.6 \mathrm{~V}$ (Figure $2 \mathrm{~A})$. The preconditioning and the cleaning steps are necessary to remove any residual metal underpotentially deposited during previous experiments. The application of this procedure regenerated the sensor surface and produced a consistent reference $\mathrm{CV}$ prior to copper detection (data not shown). The $90 \mathrm{~s}$ preconcentration time was selected based on previous work on the UPD-SV of copper at microelectrode arrays [20].

UPD-SV of copper at the eight different microelectrochemical cells was then undertaken for increasing concentrations of copper using the procedure described above. Figure $2 \mathrm{~B}$ shows the UPD-SV results for design A4 for concentrations ranging from 1 to $5 \mu \mathrm{M}$. A 
calibration curve for copper is shown in inset. For each concentration, the stripping peak current value was the average of 6 measurements. Table 2 displays different sensor parameters for designs A1-8.The sensitivity of UPD-SV depends on the diffusion type (hemispherical or linear) occurring at the microelectrodes during the preconcentration step. The diffusion type is itself related to the geometrical parameters of the microelectrochemical cells. As expected, the geometrical parameters of the microelectrode array had a strong influence on it as it varied from $0.38 \mathrm{nA} \mathrm{M}^{-1}$ for design $\mathrm{A} 1$ up to $13.59 \mathrm{nA} \mathrm{M}^{-1}$ for design A7. Good linearity between the stripping peak currents and the concentration was achieved for the designs studied. The influence of the geometry of the array (number and radius of the microdiscs and inter-electrode spacing) on the sensitivity was investigated. The sensitivity was normalised to the surface area of the microdiscs in the array for comparison purposes. The normalised sensitivity as a function of the number of microdiscs in the array is shown in Figure 3A. It can be expected that the normalised sensitivity should be constant in the case of microdiscs demonstrating independent diffusion behaviour. Nevertheless from Figure 3A, it clearly appears that the normalised sensitivity varies with the number of microdiscs in the array. Such results suggest that microdiscs do not behave independently from one another and overlap of the diffusion zones occurs. Deviation from the constant value is observed at the two arrays with the larger number of microdiscs. This can be explained by the fact that in an array, the nature of the microdiscs can be divided in two types: peripheral and central microdiscs, as illustrated in inset of Figure 3A for an array of 16 microdiscs. Central microdiscs have 6 neighbours and are more likely to suffer from overlap of the diffusion zones and hence their contribution to the total current reduces drastically. The proportion of central microdiscs in the array increases with the number of discs in the array. For design A1 $(N=4)$, there are no central microdiscs, whereas $56 \%$ of discs in design A3 $(N=64)$ and $76 \%$ of discs in design A4 $(N=256)$ are central microdiscs. This overlap between the diffusion zones is observed for the Cu UPD-SV experiments although CV experiments shown in Figure 1A demonstrated independent microdiscs. This was due to the difference between the timescale of the cyclic voltammetry of ferricyanide and the UPD-SV experiments for $\mathrm{Cu}^{2+}$ detection. Indeed, the distance between neighbouring microdiscs in an array needed to be $20 r$ to ensure hemispherical diffusion (according to the empirical rule) was valid for short timescales such as cyclic voltammetric experiments. However, in the case of UPD-SV at the end of the preconcentration step of $90 \mathrm{~s}$, the diffusion layer corresponded to $357 \mu \mathrm{m}$ thickness as follows from equation 2 [29]:

$$
\delta=\sqrt{2 D t}
$$

In this equation, $\delta$ is diffusion layer thickness, $D$ is the diffusion coefficient of copper ions ( $D$ $=7.1 \times 10^{-6} \mathrm{~cm}^{2} \mathrm{~s}^{-1}$ ) [34] and $t$ is the preconcentration time. This is in agreement with previous studies by Menshykau et al. on the concept of diffusional independence [23]. Sensitivity normalised to the surface area increases when the microdiscs decreases as is shown in Figure 3B. The sensitivity values range from $16.9 \mu \mathrm{A} \mu \mathrm{M}^{-1} \mathrm{~cm}^{-2}$ (design A7, $r=20$ $\mu \mathrm{m})$ up to $40.8 \mu \mathrm{A} \mu \mathrm{M}^{-1} \mathrm{~cm}^{-2}$ (design $\mathrm{A} 5, r=5 \mu \mathrm{m}$ ). This behaviour of the sensitivity as a 
function of the radius is expected and was also reported elsewhere [18]. Furthermore, when the inter-electrode spacing is increased from 20 times (design A3, $d=200 \mu \mathrm{m}$ ) the radius to 40 times (design $\mathrm{A} 8, d=400 \mu \mathrm{m}$ ), the sensitivity rises from 25.5 to $39.1 \mu \mathrm{A} \mu \mathrm{M}^{-1} \mathrm{~cm}^{-2}$. These results confirm that overlap of the diffusion zones occur during the deposition step of the UPD-SV experiments. Lee et al. have described diffusion at microdiscs arrays using two dimensionless parameters which are $d / r$ and $\delta / r$ [35]. The plot of $\log (d / r)$ vs $\log (\delta / r)$ can be divided in three domains where diffusion is either spherical, linear or mixed (inset of Figure 3B). These three domains are based on two equations as described by Lee et al. [35]. The limit between the hemispherical and the mixed diffusion domains is described by equation (3) and the limit between the mixed and the linear diffusion domains is described by equation (4).

$$
\begin{aligned}
& \frac{\delta}{r}=\left[\frac{d}{2 r}-1\right] / \sqrt{3} \quad \text { Eq. (3) } \\
& \frac{\delta}{r}=\sqrt{\frac{2}{\pi}}\left[\frac{\sqrt{3} d^{2}}{2 \pi r^{2}}-1\right] \quad \text { Eq. (4) }
\end{aligned}
$$

Based on the geometrical parameters of the designs tested and the preconcentration time used for the experiments reported in this article, mixed diffusion processes are obtained and correlates the results observed. In order to achieve fully hemispherical diffusion at a microdisc array, it is necessary to either shorten $\delta$ by reducing the deposition time or by increasing the inter-electrode spacing, $d$, or by a modification of both.

Limits of detection were calculated based on the $y$-intercept and slope values of the calibration curves constructed plus three times the standard deviation of the $y$-intercept values [36]. They ranged from $0.11 \mu \mathrm{M}$ to $0.39 \mu \mathrm{M}$. There was no particular trend between the limits of detection achieved and the geometrical parameters of the electrode (number of microdiscs in the array, microdisc radius, inter-microdisc distance). This may have been due to the strong presence of chloride ions in seawater, which upon adsorption on the platinum surface were capable of interfering with the copper detection [37] as the chloride anions competed with $\mathrm{Cu}$ atoms underpotentially deposited on the surface. The competition between chloride ions and $\mathrm{Cu}$ was stronger than between sulfate ions and $\mathrm{Cu}$. Therefore, the high concentration of chloride in seawater hindered the UPD of low concentration of $\mathrm{Cu}^{2+}$. Nevertheless, these limits of detection were within the concentration range of $\mathrm{Cu}^{2+}(0.036-$ $0.940 \mu \mathrm{M}$ ) which can be found in polluted seawater [28] and the reference material, where the concentration of the copper was $(2.96 \pm 0.02) \mu \mathrm{M}$. The reference material was analysed by standard addition method. UPD-SV scans on the sample were performed at design A6 microelectrochemical cell. Two standard additions of $3 \mu \mathrm{M}$ of $\mathrm{Cu}^{2+}$ were added to the sample. Experiments were done in quadruplets. The standard addition linear regression was $y$ $=1.42 x+3.44\left(r^{2}=0.970\right)$ and the concentration extracted with this equation was $(2.43 \pm$ 0.50) $\mu \mathrm{M}$ which coincided, within the accuracy of the analysis, with the known copper concentration in the sample provided. The relatively large difference between the certified $\mathrm{Cu}^{2+}$ concentration and the measured one could be due to the presence of dissolved organic matter. The reference material was used as received. As no sample preparation was used, the presence of dissolved organic matter might foul the electrode surface and hence limits the 
sensitivity of the $\mu$ disc surface. Previous studies have shown that $\mathrm{Cu}^{2+}$ UPD-SV can be inhibited by the presence of dissolved organic matter such as surfactants and humic acid [3840]. This could be avoided by the use of a permselective gel membrane [41] or by the disorganised monolayer approach [38].

The influence of parameters such as the temperature, the $\mathrm{pH}$ and the salinity of the artificial seawater on the sensitivity for $\mathrm{Cu}^{2+}$ UPD-SV for different preconcentration times (PT) of 0 , 45 and $90 \mathrm{~s}$ was also investigated (Figure 4). The environmental conditions were selected on values recorded in the Gijón port waters [28] to allow the study of behaviour of the microelectrochemical sensors in various conditions that may be encountered in the field. Sea water temperatures can vary between 283 and $303 \mathrm{~K}$ during the year. pH values have been measured between 6.5 and 8.5. Salinity is defined as the salt concentration in seawater. It is measured in practical salinity units (PSU). Salinity of seawater is measured by its conductivity. The average salinity of ocean water is 35.5 PSU, varying from less than 15 PSU at river mouths to more than $40 \mathrm{PSU}$ in the Dead Sea [42]. Calibration curves for $\mathrm{Cu}^{2+}$ at microdisc array of design A6 was built for temperatures ranging from 283 to $303 \mathrm{~K} \mathrm{(pH}$ was kept constant at 6.5, salinity was $30 \mathrm{PSU}$ ), for $\mathrm{pH}$ values between 6.5 and 8.5 ( $\mathrm{T}=298 \mathrm{~K}$, salinity $=30 \mathrm{PSU})$ ) and for salinity values between 20 and $40 \mathrm{PSU}(\mathrm{pH} 6.5$ and $\mathrm{T}=298 \mathrm{~K})$. based Figure 4A shows that the sensitivity increases linearly with the $\mathrm{T}$ range under investigation as it was observed by Jerkiewicz et al. for the $\mathrm{Cu}^{2+}$ UPD studies in acidic solutions at $\mathrm{Pt}(111)$ electrodes [43]. For $\mathrm{pH}$ values between 6.5 and 8.5, the maximum sensitivity was obtained for $\mathrm{pH} 7.5$ and the lower sensitivity was obtained for $\mathrm{pH} 8.5$ (Figure $4 \mathrm{~B}$ ), due to the increase of hydroxide ions in the artificial seawater solution. At diluted $\mathrm{Cu}^{2+}$ concentrations $\left(<10^{-5} \mathrm{M}\right)$ and at $\mathrm{pH}$ between 6.3 and 8.5, free $\mathrm{Cu}^{2+}$ concentration decreases and $\mathrm{CuOH}^{+}$and $\mathrm{Cu}(\mathrm{OH})_{2}$ forms can be found [44,45], which could explain the decrease in sensitivity at $\mathrm{pH} 8$ and 8.5. Salinity has significant influence only at the low salinity level (less than 25 PSU). At low salinity values, the concentration of the chloride in the artificial seawater is significantly lower and there is less chloride ions adsorbed on the surface of the electrode. $\mathrm{Cu}^{2+}$ ions do not need to overcome the presence of chloride ions adsorbed on the platinum to be underpotentially deposited [46]. Beyond 25 PSU, there is no significant differences between the sensitivities measured. It should also be noted that the sensitivity increases with the preconcentration times as it is expected. These results show the importance of environmental parameters ( $\mathrm{T}$ and $\mathrm{pH}$ of the sea water essentially) on the $\mathrm{Cu}^{2+}$ detection response.

\section{Conductivity measurements}

EIS experiments were run at the conductivity sensors of designs I1-4, where real, $R e Z$, and imaginary, ImZ, impedance data was recorded over the frequency range $0.1 \mathrm{~Hz}$ to $1 \mathrm{MHz}$. A range of different conductivity standard solutions were used for to investigate the performance of the different sensor designs. ReZ was used for the conductivity measurements. The correlation between $\operatorname{ReZ}$ and the conductivity, $S_{e s t}$, is detailed in the Supplementary Data. Figure 5 shows the conductivity values obtained experimentally using design I4 of the interdigitated electrode at $1 \mathrm{MHz}, S_{\text {est }}$, and using the conductometer readings 
versus the conductivity value of the standard solutions, $S_{s t d}$. Both of the sensors operated similarly at the conductivity standards less than $20.00 \mathrm{mS} \mathrm{cm} \mathrm{cm}^{-1}$ with regression equations $\mathrm{y}=0.9937 \mathrm{x}+0.0626$ for design I4 and $\mathrm{y}=0.9119 \mathrm{x}-0.3197$ for the conductometer. Nevertheless, as opposed to the interdigitated sensor the standard conductometer readings were significantly less than the actual conductivity value in the $\mathrm{KCl}$ conductivity standard $50.00 \mathrm{mS} \mathrm{cm}$. Thus, the linearity of the conductometer over the full range of the conductivity standards deteriorated compared with the interdigitated sensor $\left(r^{2}=0.9788\right.$ against $r^{2}=0.9998$ for the interdigitated sensor design I4).

\section{Conclusions}

Two different types of on-chip electrochemical sensors (three-electrode electrochemical cell and interdigitated electrodes) were studied with a view to using them for in-situ environmental monitoring.

Cyclic voltammetry of a model redox probe at the eight different designs of microdiscs arrays have shown that microdiscs in the array behave as independent electrodes. This electrochemical behaviour is in agreement with the theory described in the literature. The different designs were then compared in terms of sensitivity and limits of detection for the detection of $\mathrm{Cu}^{2+}$ in artificial seawater by UPD-SV. These experiments have shown that the microdiscs do not behave independently during the UPD-SV experiments and that mixed diffusion profiles are achieved. This overlapping diffusion zones could be avoided by either reducing the preconcentration time of the $\mathrm{Cu}^{2+} \mathrm{UPD}-\mathrm{SV}$, or by increasing the $d / r$ ratio. Nevertheless, it is not always possible to reduce the preconcentration time in reason of the low levels of $\mathrm{Cu}^{2+}$ concentration that need to be detected. Furthermore, $d / r$ cannot be increased indefinitely as it will result in a large surface area for the array and an increase of a parasitic capacitance of the corresponding non-active array area. Sensitivity of the sensors were measured for a variety of environmental conditions $(283 \mathrm{~K}<\mathrm{T}<303 \mathrm{~K} ; 6.5<\mathrm{pH}<8.5$ and 20 PSU < salinity < $40 \mathrm{PSU})$. $\mathrm{T}$ and $\mathrm{pH}$ had the strongest influence on the sensor response suggesting that for accurate in-situ measurements, the corresponding environmental sensors should be introduced into the sensing system. Their reading should be used to compensate the sensor measurement against $\mathrm{T}, \mathrm{pH}$ and salinity.

Four designs of interdigitated electrodes were tested for the measurement of conductivity of seawater. Best results were obtained for measurements at high frequencies $(f>10 \mathrm{kHz})$.

The dynamic range and limit of detections achieved for $\mathrm{Cu}^{2+}$, dissolved oxygen and conductivity were within the range of concentration observed in real samples of port seawater.

\section{Acknowledgments}

The authors thank the European Commission for supporting this work (Project FP7-ICT231646 "SHOAL: Search and monitoring of harmful contaminants, other pollutants and leaks in vessels in port using a swarm of robotic fishes"). The authors are grateful to Prof. Dmitri Papkovsky and Dr Grzegorz Jasionek from the University College Cork Department of Biochemistry for access to the precision gas mixer. The authors are also grateful to the Port 
Authority of Gijón for the provision of environmental data.

\section{References}

[1] X.J. Huang, A.M. O’Mahony, R.G. Compton, Small 5 (2009) 779.

[2] E.P. Achterberg, C.M.G. van den Berg, C. Colombo, Continental Shelf Research 23 (2003) 611-623.

[3] C. Colombo, C.M.G. Van den Berg, A. Daniel, Anal. Chim. Acta 346 (1997) 101-111.

[4] M. Lou Tercier, J. Buffle, F. Graziottin, Electroanalysis 10 (1998) 355-363.

[5] M.-L. Tercier-Waeber, F. Confalonieri, G. Riccardi, A. Sina, S. Nöel, J. Buffle, F. Graziottin, Marine Chemistry 97 (2005) 216-235.

[6] C. Belmont, M. Lou Tercier, J. Buffle, G.C. Fiaccabrino, Anal. Chim. Acta 329 (1996) 203-214.

[7] R. Feeney, S. Kounaves, Anal. Chem. 72 (2000) 2222-8.

[8] M. Sosna, G. Denuault, R.W. Pascal, R.D. Prien, M. Mowlem, Limnology and Oceanography 6 (2008) 180-189.

[9] M. Sosna, G. Denuault, R.W. Pascal, R.D. Prien, M. Mowlem, Sensor. Actuat. B 123 (2007) 344-351.

[10] J. Buffle, M.-L. Tercier-Waeber, TrAC Trend Anal. Chem. 24 (2005) 172-191.

[11] K. Malzahn, J.R. Windmiller, G. Valdés-Ramírez, M.J. Schöning, J. Wang, Analyst 136 (2011) 2912-2917.

[12] B. O’Flynn, F. Regan, A. Lawlor, J. Wallace, J. Torres, C. O’Mathuna, Meas. Sci. Technol. 21 (2010) 124004.

[13] A. Lawlor, J. Torres, B. O’Flynn, J. Wallace, F. Regan, Sensor Review 32 (2012) 2938.

[14] G. Mills, G. Fones, Sensor Review 32 (2012) 17-28.

[15] T.S. Moore, K.M. Mullaugh, R.R. Holyoke, A.S. Madison, M. Yücel, G.W. Luther, Annual Review of Marine Science 1 (2009) 91-115.

[16] K.S. Johnson, J. a Needoba, S.C. Riser, W.J. Showers, Chem. Rev. 107 (2007) 62340.

[17] R.D. Prien, Marine Chemistry 107 (2007) 422-432. 
[18] A. Berduque, Y.H. Lanyon, V. Beni, G. Herzog, Y.E. Watson, K. Rodgers, F. Stam, J. Alderman, D.W.M. Arrigan, Talanta 71 (2007) 1022-1030.

[19] A. Berduque, G. Herzog, Y.E. Watson, D.W.M. Arrigan, J.-C. Moutet, O. Reynes, G. Royal, E. Saint-Aman, Electroanalysis 17 (2005) 392-399.

[20] W. Moujahid, P. Eichelmann-Daly, J. Strutwolf, V.I. Ogurtsov, G. Herzog, D.W.M. Arrigan, Electroanalysis 23 (2011) 147-155.

[21] G. Herzog, D.W.M. Arrigan, TrAC Trend Anal. Chem. 24 (2005) 208-217.

[22] J. Guo, E. Lindner, Anal. Chem. 81 (2009) 130-8.

[23] D. Menshykau, X.-J. Huang, N. V Rees, F.J. del Campo, F.X. Muñoz, R.G. Compton, Analyst 134 (2009) 343-348.

[24] G. Herzog, V. Beni, Anal. Chim. Acta 769 (2013) 10-21.

[25] J. McLaghlan, Canadian Journal of Microbiology 10 (1964) 769-782.

[26] J.C. Goldman, J.J. McCarthy, Limnology and Oceanography 23 (1978) 695-703.

[27] I. Hansson, Acta Chemica Scandinavia 27 (1973) 931-944.

[28] Environmental Information, Port Authority of Gijón, Spain, 2010.

[29] A.J. Bard, L.R. Faulkner, Eletrochemical Methods: Fundamentals and Applications, John Wiley and Sons, 2001.

[30] M. von Stackelberg, M. Pilgram, V. Toome, Z. Elektrochemie 57 (1953) 342-345.

[31] O. Ordeig, C.E. Banks, T.J. Davies, J. Del Campo, R. Mas, F.X. Muñoz, R.G. Compton, The Analyst 131 (2006) 440-5.

[32] C.G. Zoski, N. Simjee, G. Street, O. Guenat, M. Koudelka-hep, Anal. Chem. 76 (2004) 62-72.

[33] A.M. O’Mahony, Heavy Metal Sensors for Remediation of River and Sea Water, University College Cork, 2007.

[34] A.E. Marcinkowsky, H.O. Phillips, J. Chem. Soc. A (1971) 101-103.

[35] H.J. Lee, C. Beriet, R. Ferrigno, H.H. Girault, J. Electroanal. Chem. 502 (2001) 138145 .

[36] R. Caulcutt, R. Boddy, Statistics for Analytical Chemists, Chapman and Hall, 1983.

[37] N. Markovic, P.N. Ross, Langmuir 9 (1993) 580-590.

[38] G. Herzog, D.W.M. Arrigan, Anal. Chem. 75 (2003) 319-23. 
[39] G. Herzog, D.W.M. Arrigan, Electroanalysis 15 (2003) 1302-1306.

[40] G. Herzog, V. Beni, P.H. Dillon, T. Barry, D.W.M. Arrigan, Anal. Chim. Acta 511 (2004) 137-143.

[41] C. Belmont-Hébert, M.-L. Tercier-Waeber, J. Buffle, G.C. Fiaccabrino, N.F. De Rooij, M. Koudelka-Hep, Anal. Chem. 70 (1998) 2949-2956.

[42] L.D. Talley, in:, M.C. MacCracken, J.S. Perry (Eds.), Encyclopedia of Global Environmental Change, John Wiley and Sons, Chichester, 2002, pp. 629-640.

[43] G. Jerkiewicz, F. Perreault, Z. Radovic-Hrapovic, J. Phys. Chem. C 113 (2009) 12309-12316.

[44] C.F. Baes Jr, R.E. Mesmer, Hydrolysis of Cations, John Wiley and Sons, New York, 1976.

[45] A.J. Paulson, D.R. Kester, J. Sol. Chem. 9 (1980) 269-277.

[46] H.S. Yee, H.D. Abruña, Langmuir (1993) 2460-2469. 


\section{Figure captions}

Figure 1: Cyclic voltammetry of $1 \mathrm{mM}$ ferricyanide in artificial seawater using microelectrochemical cells of (A) designs A1-4 (voltammograms from top to bottom). Inset: $i_{\text {lim }}$ as a function of $N$; (B) designs A3, A5-7. Inset: limiting current density as a function of $r$; (C) designs $\mathrm{A} 3$ and $\mathrm{A} 8$. The scan rate was $10 \mathrm{mV} \mathrm{s}^{-1}$.

Figure 2: (A) Potential waveform for the $\mathrm{Cu}^{2+}$ UPD-SV experiments at the different microelectrochemical cell designs. (B) UPD-SV of $\mathrm{Cu}^{2+}\left(0<\left[\mathrm{Cu}^{2+}\right]<5 \mu \mathrm{M}\right)$. Inset: Calibration curve of the $\mathrm{Cu}^{2+}$ stripping current as a function of the $\mathrm{Cu}^{2+}$ concentration in artificial seawater.

Figure 3: (A) Sensitivity normalised to the surface area as a function of microdiscs in the array $(\mathbf{\Delta})$. The straight line represents the expected behaviour if microdiscs in the array were independent from one another. Inset: Schematic representation of the array (design A2) where (๑) are the peripheral microdiscs and (O) are the central microdiscs. (B) Sensitivity normalised to the surface area as a function of microdisc radius. Inset: Plot of log $d / r$ vs. lod $\delta / r$ for electrodes of designs A1-A4 and A8. The solid line is described by equation (3) and the dotted line by equation (4) [35].

Figure 4: Sensitivity achieved using design A6 as a function of (A) temperature (pH 6.5, 30 PSU), (B) $\mathrm{pH}(\mathrm{T}=298 \mathrm{~K}, 30 \mathrm{PSU})$ and (C) salinity ( $\mathrm{T}=298 \mathrm{~K}, \mathrm{pH} 6.5)$ of the artificial seawater. $\mathrm{Cu}^{2+}$ concentration range was $0.5-3.0 \mu \mathrm{M}$ for different preconcentration times: $(\bullet) \mathrm{PT}=0 \mathrm{~s},(\square) \mathrm{PT}=45 \mathrm{~s}$ and $(\boldsymbol{\square}) \mathrm{PT}=90 \mathrm{~s}$ ).

Figure 5: Experimental conductivity measured using $(\circ)$ interdigitated electrodes of design I4 at $1 \mathrm{MHz}$ and $(\square)$ a commercial probe and conductometer at $2.4 \mathrm{kHz}$ as a function of a function of the conductivity of $\mathrm{KCl}$ standard solutions. If not visible, the error bars are smaller than the symbols.

Table 1: Geometrical parameters of the different microchemical cells designed (A1-8 \& I14).

Table 2: Analytical performances for the $\mathrm{Cu}^{2+} \mathrm{UPD}-\mathrm{SV}$ at the different microelectrochemical cells designed (A1-8). 
Figure 1

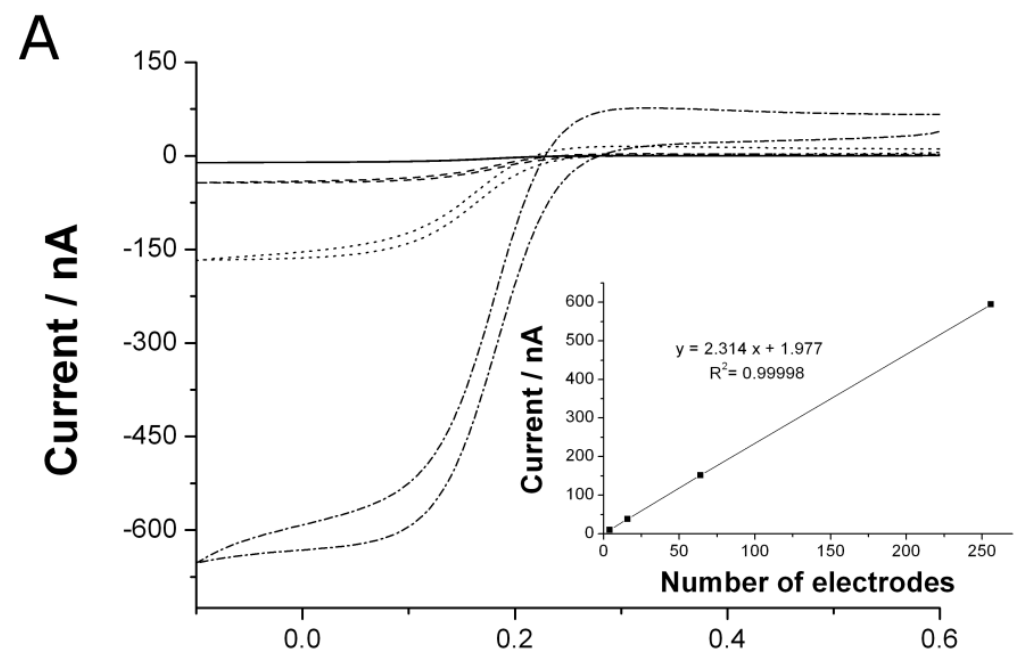

Potential / V
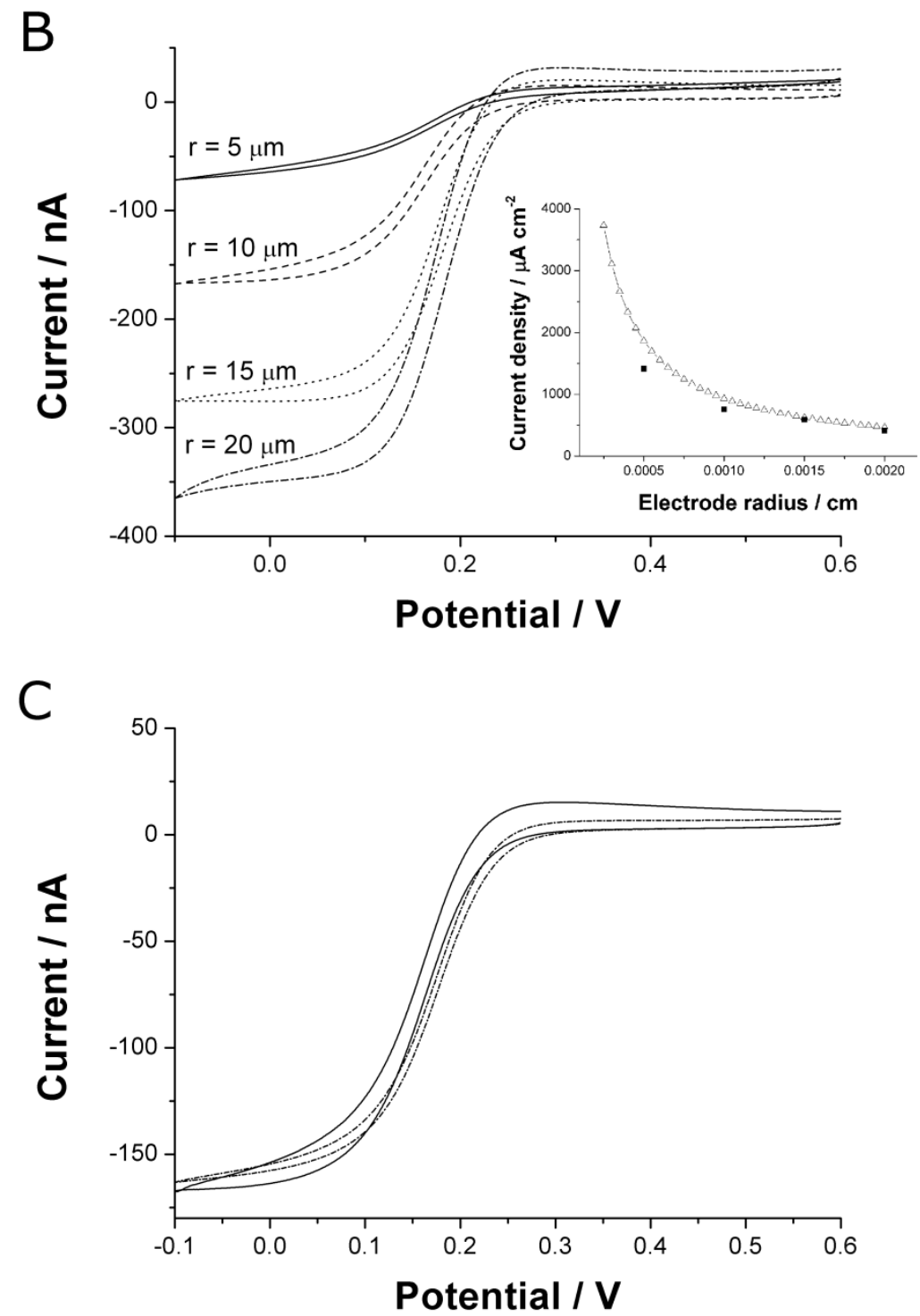
Figure 2
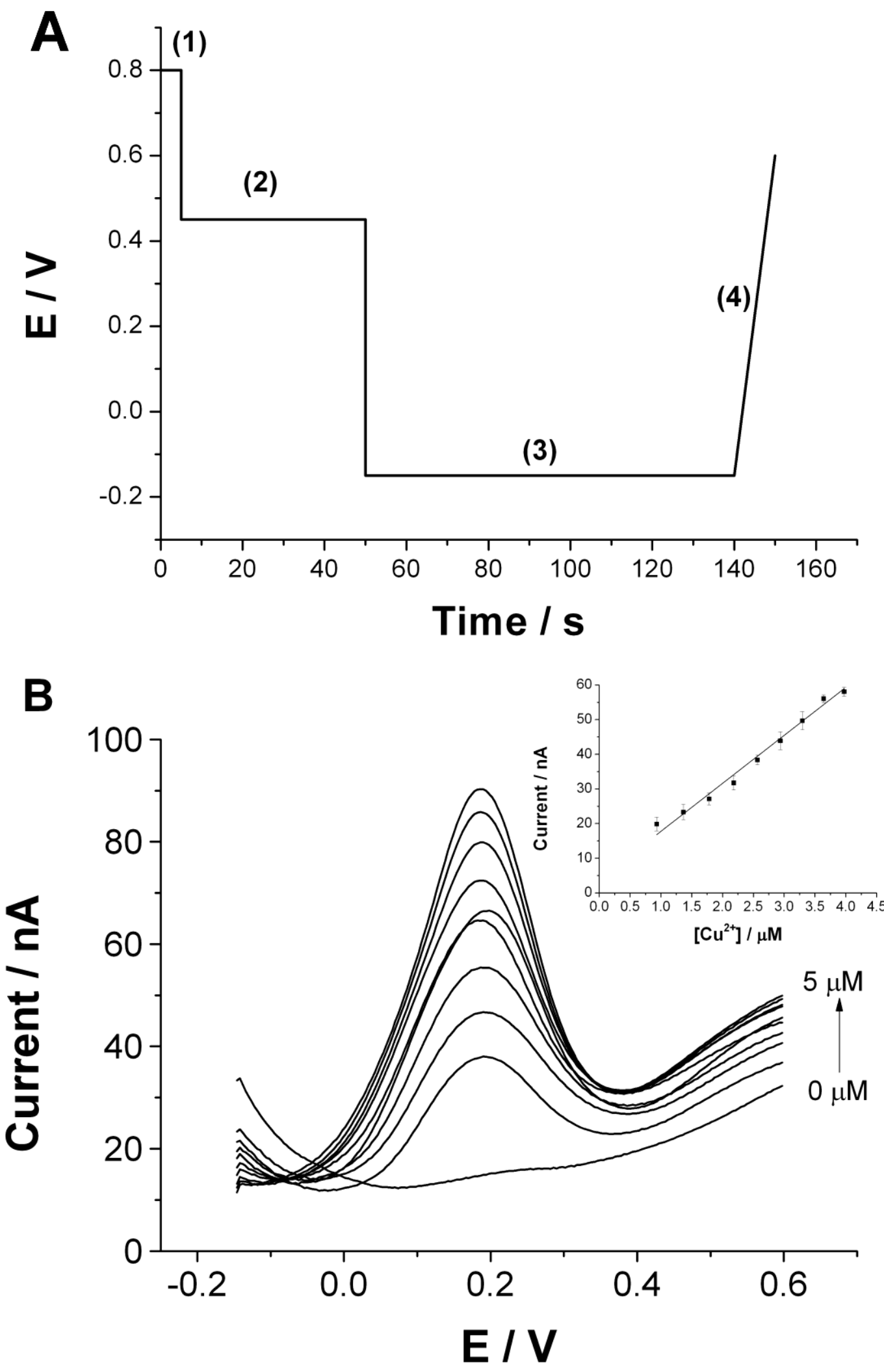
Figure 3
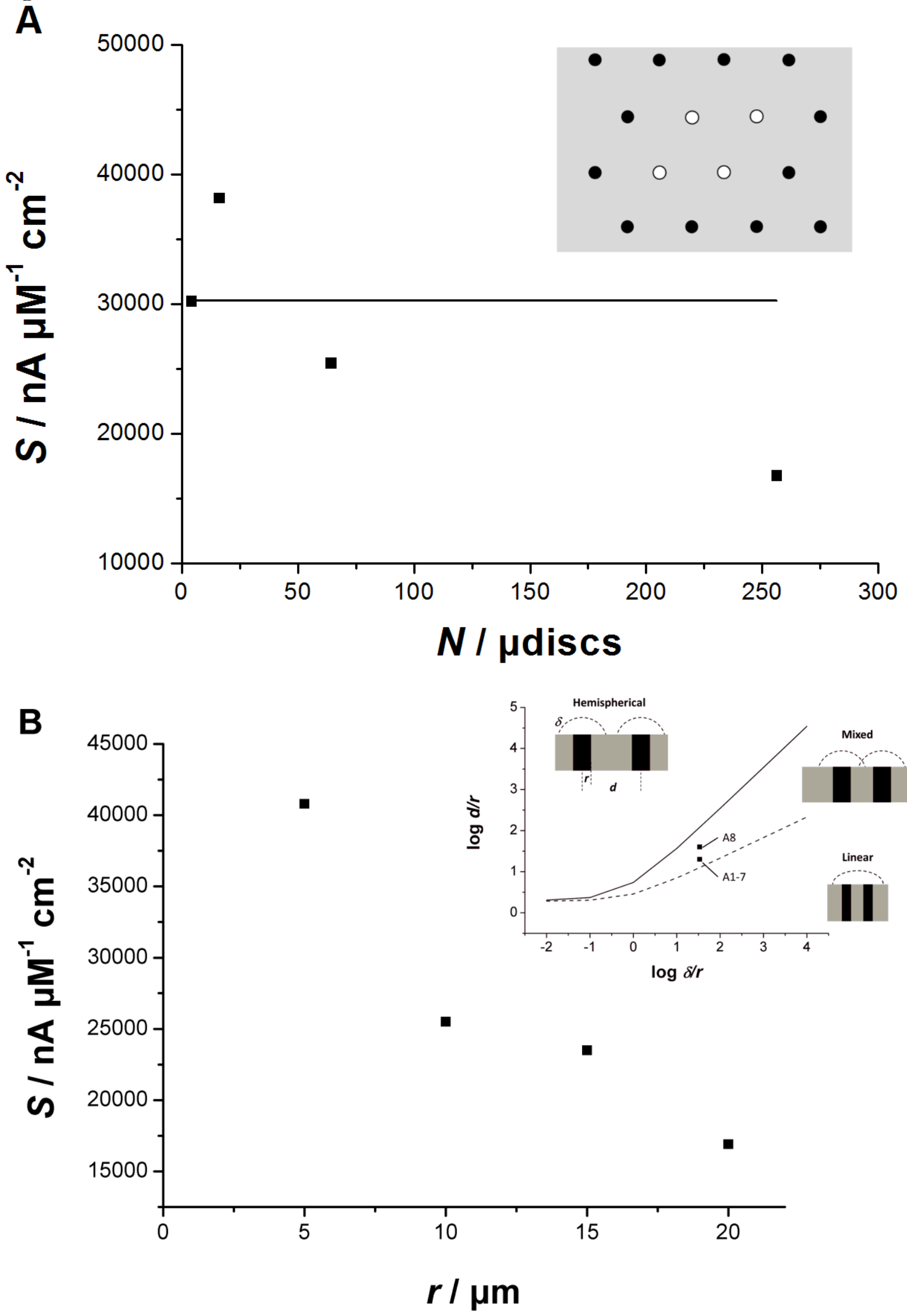
Figure 4

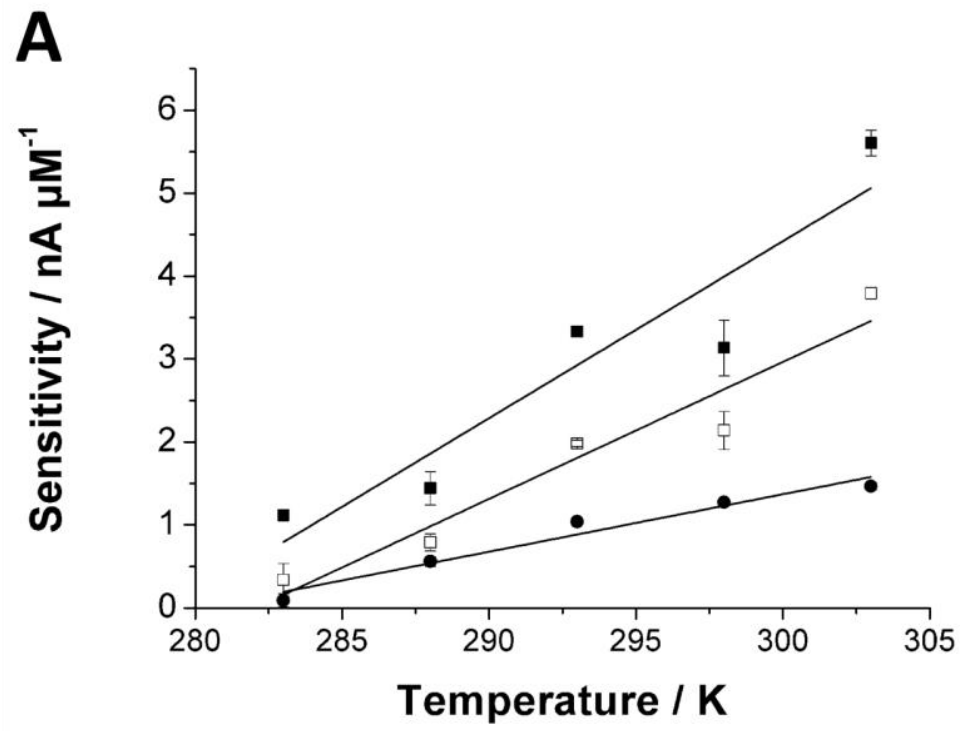

B

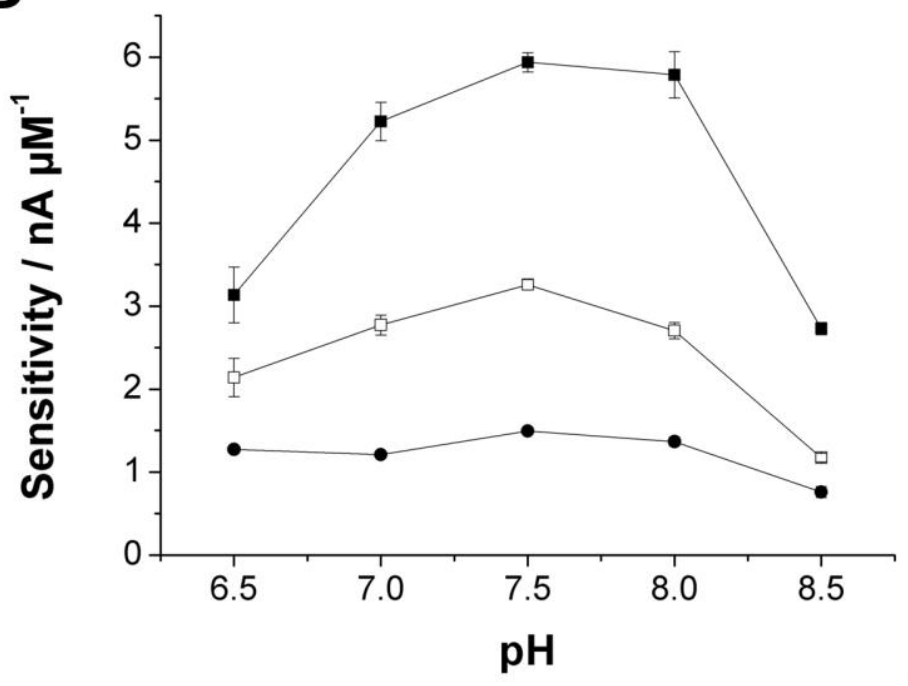

C

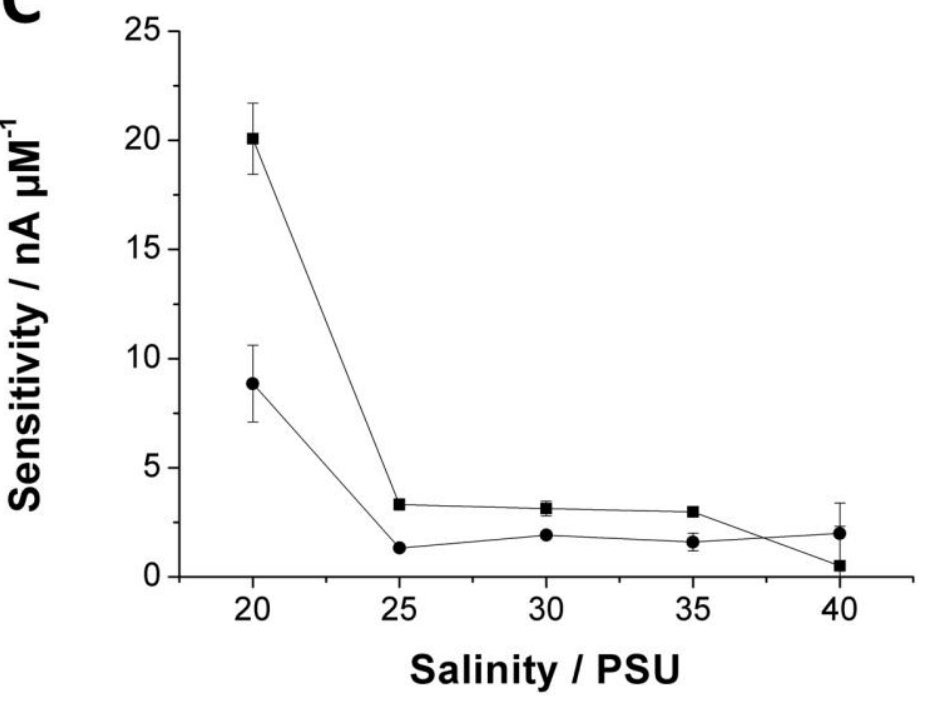


Figure 5

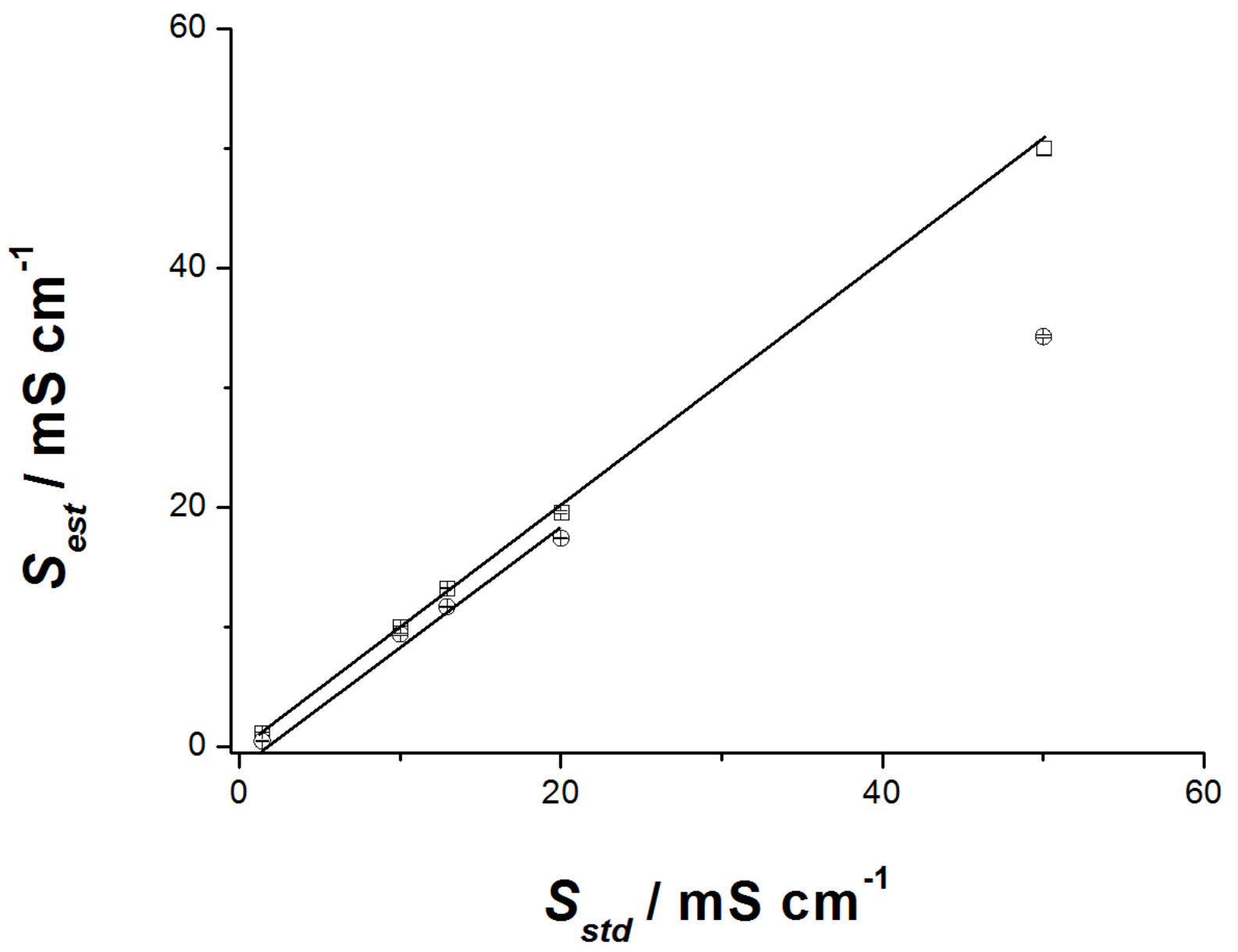


Table 1

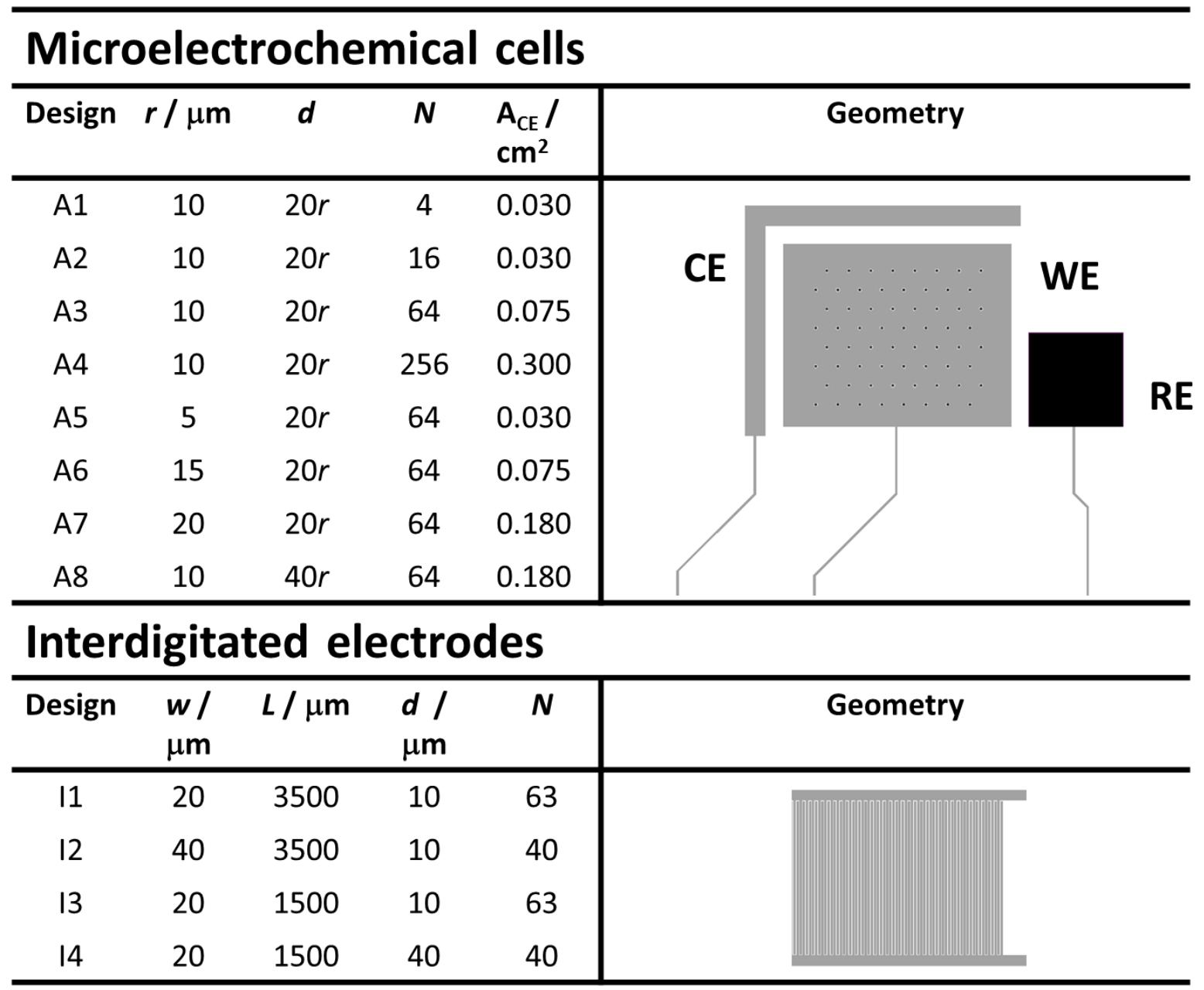

$r$ : radius of the microdisc, $d$ : interelectrode distance; $N$ : Number of elements in the array; $\mathrm{A}_{\mathrm{CE}}$ : Surface area of the counter electrode; CE: Counter electrode; WE: Working electrode; RE: Reference electrode; $w$ : width; $L$ : length. 
Table 2

\begin{tabular}{ccccccc}
\hline Design & $\begin{array}{c}\text { Dynamic Range } \\
\mu \mathrm{M}\end{array}$ & $\begin{array}{c}\text { Sensitivity } \\
\mathrm{nA} \boldsymbol{\mu} \mathbf{M}^{-1}\end{array}$ & $\begin{array}{c}\text { Sensitivity } \\
\boldsymbol{\mu A} \boldsymbol{\mu} \mathbf{M}^{-1} \mathbf{c m}^{-2}\end{array}$ & $\begin{array}{c}\text { Intercept } \\
\mathrm{nA}\end{array}$ & $\boldsymbol{R}^{\mathbf{2}}$ & $\begin{array}{c}\text { LOD } \\
\boldsymbol{M} \mathbf{M}\end{array}$ \\
\hline $\mathrm{A} 1$ & $0.48-3.97$ & 0.38 & 30.2 & 0.18 & 0.990 & 0.34 \\
$\mathrm{~A} 2$ & $0.48-2.94$ & 1.92 & 38.2 & 1.35 & 0.998 & 0.11 \\
$\mathrm{~A} 3$ & $0.93-3.97$ & 5.12 & 25.4 & 2.30 & 0.994 & 0.24 \\
$\mathrm{~A} 4$ & $0.93-3.97$ & 13.49 & 16.8 & 4.69 & 0.986 & 0.39 \\
$\mathrm{~A} 5$ & $0.48-2.94$ & 2.05 & 40.8 & 2.70 & 0.988 & 0.30 \\
$\mathrm{~A} 6$ & $0.59-2.91$ & 5.42 & 23.5 & 11.70 & 0.988 & 0.28 \\
$\mathrm{~A} 7$ & $0.48-2.94$ & 13.59 & 16.9 & 5.90 & 0.996 & 0.13 \\
$\mathrm{~A} 8$ & $0.48-2.94$ & 7.87 & 39.1 & 6.32 & 0.992 & 0.23 \\
\hline
\end{tabular}

